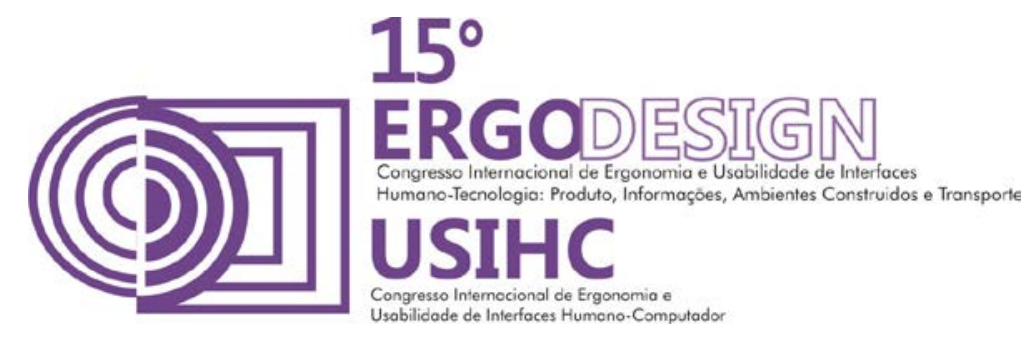

\title{
APROPRIAÇÃO ESPACIAL DAS CRIANÇAS - UM ESTUDO ERGONÔMICO NO PÁTIO ESCOLAR
}

\section{APPROPRIATION OF CHILDREN: AN ERGONOMIC STUDY IN THE SCHOOL YARD}

\author{
SAVI, Aline Eyng (1); \\ RECH, Gracielle Rodrigues da Fonseca (2) \\ (1) Universidade Federal de Santa Catarina, Doutoranda em Arquitetura e Urbanismo \\ e-mail: arquiteta.alinesavi@gmail.com \\ (2) Universidade Federal de Santa Catarina, Mestranda em Arquitetura e Urbanismo \\ e-mail: graciellerfrech@hotmail.com
}

\begin{abstract}
RESUMO
A escola é ambiente de experiências da criança com a participação na vida coletiva. Nela, o pátio incorpora complexidade e diversidade de funções. Com o objetivo de avaliar as suas condições físicas e as relações com a apropriação das crianças, para adequá-las às exigências específicas; o artigo apresenta o estudo de caso no pátio do Colégio de Aplicação da Universidade Federal de Santa Catarina. Para o estudo foram utilizados: Observação, Levantamento Arquitetônico e Entrevista, que resultaram na leitura espacial. A territorialidade mostrou-se fundamental para delimitar os postos de atividades e para propor sugestões e recomendações projetuais.
\end{abstract}

Palavras chave: Ergonomia, Pátio escolar, Crianças

\section{ABSTRACT}

The school is child's experiences environment to participation in collective life. In it, the courtyard incorporates complexity and diversity of functions. In order to assess their physical conditions and relations with the appropriation of children, to adapt them to the specific requirements; the article presents a case study on Colégio de Aplicação of the Universidade Federal de Santa Catarina. The following were applied: observation, Architectural Survey and interviews, which resulted in spatial reading. The territoriality was essential to define the activities stations and to offer suggestions and recommendations.

Keywords: Ergonomics, School yard, Children

\section{INTRODUÇÃO}

O desenvolvimento humano ocorre num cenário complexo e dinâmico, onde o ambiente físico 


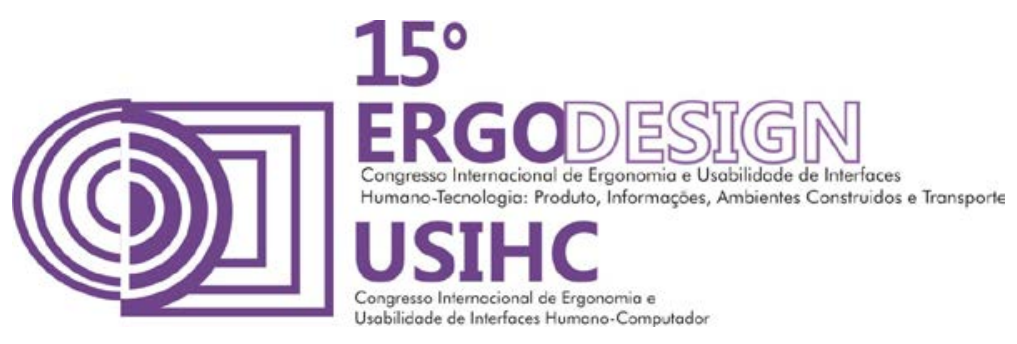

assume duas funções. Uma de contexto para aplicação de condutas. Outra de condição, recurso e instrumento para o desenvolvimento. Nesse sentido, os elementos que compõem o ambiente encontram-se interligados numa rede de experiências.

A primeira rede está na casa e num processo evolutivo, a escola é a segunda. Ela tem participação na vida coletiva com possibilidade de ensinar direitos, deveres e respeito ao próximo. É onde uma pessoa se constitui como ser pensante e questionador. A escola pode conservar isso, despertando em seus alunos potenciais criativos, curiosidades, talentos ou pode minimizar todas essas formas de expressão.

A educação carrega tal importância que avança além da pedagogia, constituindo estudo para diferentes áreas dos conhecimentos. Do ponto de vista da Arquitetura, um bom espaço físico escolar, expressado pelos aspectos perceptivos - conceituais, formais e estéticos - é aquele reconhecido pela representatividade, afirma Kowaltowski (2011). Ainda, parâmetros centrados nas vivências e usos nos ambientes como: funcionalidade, ergonomia, usabilidade, identidades com a pedagogia e com a cultura, conforto ambiental, equipamentos e mobiliário, e a infraestrutura corroboram para a apropriação escolar.

Um dos espaços físicos mais representativos das experiências sociais na escola é o pátio. Ele pode potencializar o processo educativo e ser capaz de incorporar o valor de aula, ou apenas atuar como espaço entre as atividades. A complexidade e diversidade de funções justificam 0 interesse na pesquisa desse recorte.

Assim, o artigo apresenta o estudo de caso no pátio do Colégio de Aplicação da Universidade Federal de Santa Catarina (UFSC) campus Florianópolis, Santa Catarina, Brasil. Justifica-se porque o pátio é espaço livre, atuante como palco das relações sociais e das apropriações individuais e coletivas. Dessa maneira, estuda-lo permite reconhecer as riquezas e a complexidade da apropriação do lugar.

O objetivo geral é avaliar as condições físicas do espaço e as relações com a apropriação das crianças, para adequá-las às exigências específicas dos usuários em questão. As reflexões articulam-se em torno de três objetivos específicos: (1) detectar e descrever as atividades cotidianas realizadas no pátio e relacionadas com a apropriação; (2) diagnosticar as necessidades e os problemas ergonômicos encontrados pelos usuários no desenvolvimento das atividades cotidianas; (3) propor sugestões e recomendações projetuais para viabilizar as atividades realizadas, considerando a especificidade e as características dos usuários em questão.

Afinal, conforme Bins Ely (2003), a responsabilidade em projetar os ambientes deve ir além da eficiência no conforto e na segurança, pressupõem atender às necessidades de seus usuários aos níveis fisiológico e simbólico, a fim de exercer impacto positivo sobre os mesmos.

A pesquisa é parte das atividades desenvolvidas na disciplina de "Atributos dos elementos arquitetônicos e suas relações com habitabilidade e sustentabilidade" do Programa de Pósgraduação em Arquitetura e Urbanismo da UFSC.

\section{APROPRIAÇÃO ESPACIAL}

A apropriação espacial faz parte do esquema de conduta desenvolvido na relação entre 


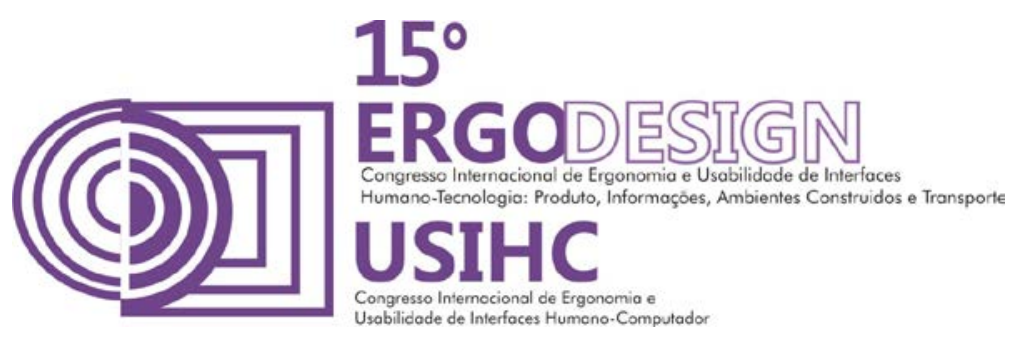

indivíduo e ambiente. Os fenômenos existenciais expressam as necessidades humanas e precisam ser consideradas quando se projeta um ambiente construído (ALMEIDA, 1995). Cada fenômeno relaciona-se com determinados reguladores espaciais permitindo ocupação, leitura, reinterpretação e/ou modificação pelos usuários. O ambiente construído interage com 0 ambiente social, cultural e psicológico. É fruto do comportamento humano e resultado de uma série de padrões e normas sociais que, por consequência, influenciarão as atividades ali realizadas (OKAMOTO, 2002). Ainda, a sensação de equilíbrio entre capacidades e desafios ambientais na apropriação espacial, influencia os níveis de estresse e o bem-estar (BINS ELY, 2003).

No projeto de ambientes para crianças, é preciso avaliar cuidadosamente vários aspectos espaciais. Os ambientes bem projetados, segundo Trancik e Evans (1995), podem aumentar a competência dos usuários na apropriação ambiental, permitindo que façam uso das suas capacidades, ao mesmo tempo em que são estimulados a desenvolver habilidades mais complexas, além do nível de desenvolvimento em que estejam.

A etimologia da palavra pátio - do latim: Pateo - o define como: estar aberto; exposto; estenderse; abrir-se; manifestar-se; ser evidente. As palavras sugerem o conceito de relacionamento com o ambiente físico, a cultura, as pessoas, etc. Como espaço de aprendizagem, o pátio ideal deve possuir mais que quadras e parques infantis, que são equipamentos encontrados em outras edificações; precisa servir de local complementar ao aprendizado, procurando oferecer transição entre espaços abertos ao ar livre e cobertos, com possibilidades diversas de usos e apropriações.

Segundo Gonçalves e Flores (2011), uma boa arquitetura de pátio escolar deve atender: (1) o contato social para permitir o desenvolvimento das habilidades de comunicação que não são feitas em sala de aula, mas desejadas para o desenvolvimento, como o diálogo espontâneo; (2) brincar e jogar, nem sempre permitidas em sala, mas que são atividades lúdicas e desenvolvem a capacidade do trabalho em equipe; (3) motricidade e os sentidos, a partir de atividades que permitam o exercício do corpo e o desenvolvimento de habilidades motoras de coordenação e força, por exemplo: subir, escalar, pular e correr. Todas são ações que permitem à criança conhecer-se melhor e ter controle maior sobre o seu corpo, aumentando a autoestima e a confiança em si mesmo; (4) as funções pedagógicas quando o espaço livre serve como exemplo ou complemento do conteúdo apresentado; (5) a função ambiental - com a aproximação do meio ambiente e da própria educação ambiental.

Apesar dessa importante função que influencia todo o processo de desenvolvimento infantil, há poucas reflexões sobre a concepção de pátios escolares no Brasil, segundo Azevedo; Rheingantz; e Tângari, 2011. "É comum, no processo projetual que a área destinada ao pátio seja tratada e concebida como mero espaço residual - "sobra" do terreno -, inadequado para as atividades de recreação, exploração, convívio e socialização das crianças" (AZEVEDO; RHEINGANTZ; TÂNGARI, 2011, p.13).

Outra característica que aponta o pátio escolar como espaço residual é que as atividades diversas de apoio ao processo pedagógico, entre elas as lúdicas, encontram-se dispersas no programa. Os pátios e as áreas livres das escolas têm sido reduzidos ou até mesmo eliminados; e quando existem são geralmente pouco convidativos ou acumulam outras funções, como extensão do refeitório e área de circulação. 


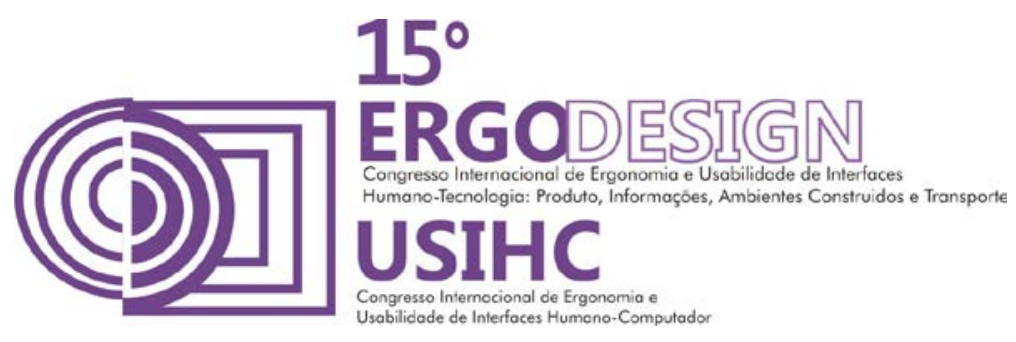

Como espaço de socialização, o pátio escolar é um ambiente singular, formado por complexos espaços próximos e distais, psicologicamente arranjados numa hierarquia, onde cada um pode ser subdividido em outros menores. Se essa gama de componentes do ambiente está em harmonia com a apropriação espacial, haverá ajuste entre ambos, mas se houver obstáculos à apropriação, pode-se comprovar o desajuste entre o ambiente e o padrão de comportamento.

Dentre os reguladores espaciais que gerenciam a apropriação, a territorialidade é uma das mais presentes no ambiente escolar. A territorialidade pode ser definida como um ambiente que as pessoas reconhecem, personalizam, demarcam, possuem e defendem. Hall (2005, p.14-16) define como:

[...] o comportamento através do qual um ser vivo declara suas pretensões em uma extensão de espaço. [...] O território tem um papel na determinação de um sistema de comportamento, define o lugar de aprender, julgar, proteger-se, etc. [...]. A territorialidade está relacionada também a hierarquia: o mais fortedominante tem um território mais amplo e acesso ao território do mais fracodominado.

Na relação entre território e crianças destaca-se que: "[...] para além das diferenças individuais, as crianças distribuem-se na estrutura social segundo a classe social, a etnia a que pertencem, o gênero e a cultura" (SARMENTO; PINTO, 1997, p.22). Isso coloca a organização de territórios como limites entre diferenças, criando uma estreita relação entre identidade infantil e os territórios de infância. A criança possui capacidades precoces em termos de uso social do espaço e de construção e administração de suas relações sociais.

A série de mecanismos para apropriação espacial determina os lugares de vivência humana. Possuir "o seu lugar" é uma necessidade inerente ao ser humano, quer esteja ligada à noção de abrigo e proteção, ou relacionada à sua posição dentro da sociedade. Possuir a imagem do "seu espaço habitado" serve para afirmar a identidade (HEIDEGGER, 2002-2004). No pátio, há a necessidade de permitir diferentes territórios e a sua identidade.

Dessa forma, as interações que se estabelecem entre sujeitos e lugares - entre a criança e o pátio escolar - não são uma mera relação física, mas uma relação carregada de sentido e mediada pelos demais sujeitos que o ocupam. Nesse sentido, na apropriação e constituição do território, mescla-se uma dimensão simbólica. Afinal, como afirma Bins Ely (2004, p. 21) a responsabilidade no projeto de ambientes deve ir além do conforto e da segurança necessidades funcionais, "pressupõe, também, compreender suas necessidades formais e estéticas a fim de assegurar um espaço agradável, de prazer e bem-estar". Nessa perspectiva, apresenta-se a seguir o estudo de caso realizado.

\section{ESTUDO ERGONÔMICO}

Os estudos ergonômicos baseiam-se na aplicação conjunta de vários conhecimentos. De forma a obter dados sobre o homem e o seu trabalho, visando melhor adaptá-lo, ou seja, é o estudo do comportamento humano frente às interfaces, conforme afirmam Ribeiro e Mont'Alvão (2004). Os elementos relativos ao ambiente que devem ser considerados são aqueles referentes ao conforto, à percepção ambiental, aos materiais de revestimentos e acabamentos e aos postos de trabalho - layout e mobiliário - considerando, também, os dados antropométricos. 


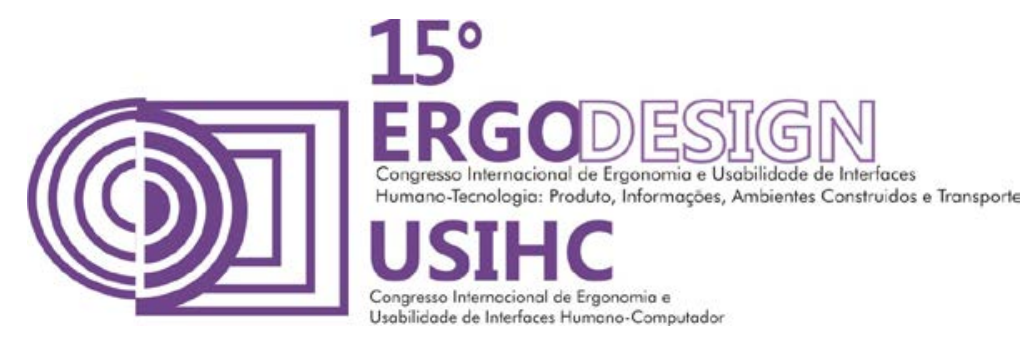

Assim, a obtenção dos dados necessários baseou-se na combinação dos seguintes instrumentos metodológicos: Observação, Levantamento Arquitetônico e Entrevista, que resultaram na leitura espacial e serviram para coletar informações de fonte primária (crianças). Os diferentes instrumentos são descritos resumidamente nos parágrafos seguintes. Cabe ressaltar que houve uma sequência para a aplicação de cada um e a opção de suas combinações visou complementar as limitações para o estudo de caso de cada um.

A sequência desses instrumentos teve a seguinte questão a ser respondida: "Quais as condições físicas do espaço para a apropriação e definição de territórios do pátio escolar?", visando abordar as relações físicas e simbólicas estabelecidas com o espaço.

\subsection{Observação}

A observação não participante contou com a elaboração de relatório escrito, onde foram registrados todos os fatos e fenômenos referentes às atividades realizadas e à sociabilidade interações entre usuário-ambiente e usuário-usuário, que serviram de embasamento para as leituras das características de uso e apropriação do espaço do pátio. Nelas as crianças foram observadas realizando suas atividades cotidianas no pátio, sem saber que estavam sendo estudadas. Para complementar, foram feitos registros de vídeos e fotos.

\subsection{Levantamento Arquitetônico}

O levantamento arquitetônico foi realizado a partir de planilhas elaboradas para sistematizar. Elas orientaram na descrição dos seguintes itens: arranjo espacial e os atributos que permitiam apropriação espacial, correspondendo à: sociabilidade - interações entre usuário-ambiente e usuário-usuário; o mobiliário do pátio e seu estado de conservação; a qualidade dos materiais de acabamento (piso, parede e teto). Relataram-se as características e o grau de danificação destes elementos, bem como as características gerais dos usuários (especialmente crianças). Para auxiliar na aplicação da planilha foram utilizadas as técnicas de registro fotográfico e medição in loco. Os registros em tópicos na planilha foram, posteriormente, transcritos.

\subsection{Entrevista}

As entrevistas seguiram a sistematização de Marconi e Lakatos (1996). Todas foram gravadas, transcritas e tratadas por análise de conteúdo. Foram realizadas entrevistas estruturadas com a coordenação pedagógica. Os tópicos definidos foram: identificação do perfil e dos hábitos das crianças no pátio escolar; a caracterização das tarefas ali realizadas e a rotina de usos.

Com as crianças que estavam no pátio durante as observações, foram aplicadas entrevistas não estruturadas. A escolha do instrumento deu-se porque as perguntas abertas se moldavam às diferentes situações e respostas. Através destas entrevistas, as crianças puderam relatar suas impressões e expectativas quanto ao espaço do pátio. Tais relatos foram utilizados para confirmar os pontos positivos e negativos levantados pelos demais instrumentos.

\section{RESULTADOS: SUGESTÕES E RECOMENDAÇÕES PROJETUAIS}

O Colégio de Aplicação da UFSC foi fundado em 1961. É uma unidade educacional que atende 


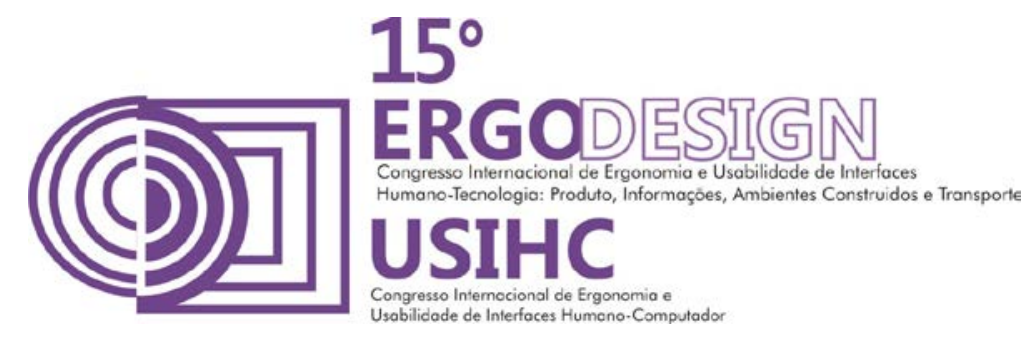

ao ensino fundamental e médio. Está localizado no Campus Universitário no município de Florianópolis. É um colégio que se propõe à produção, transmissão, construção e apropriação crítica do conhecimento, bem como a sua divulgação, com a finalidade de dar instrumentos aos educandos e aos educadores para a responsabilidade social, contribuindo para o exercício da cidadania.

O Colégio funciona em prédio próprio dividido em cinco blocos, que abrigam diversas funções (figura 01). A estrutura passou por diferentes ampliações, refletida na tipologia distinta dos blocos que acompanha os diferentes períodos em que foram projetados e edificados.

A unidade dessa arquitetura ocorre pela materialidade de acabamento, com a pintura de cores uniformes nos blocos. A união na implantação acontece pelos caminhos/fluxos entre os corredores e passarelas cobertas.

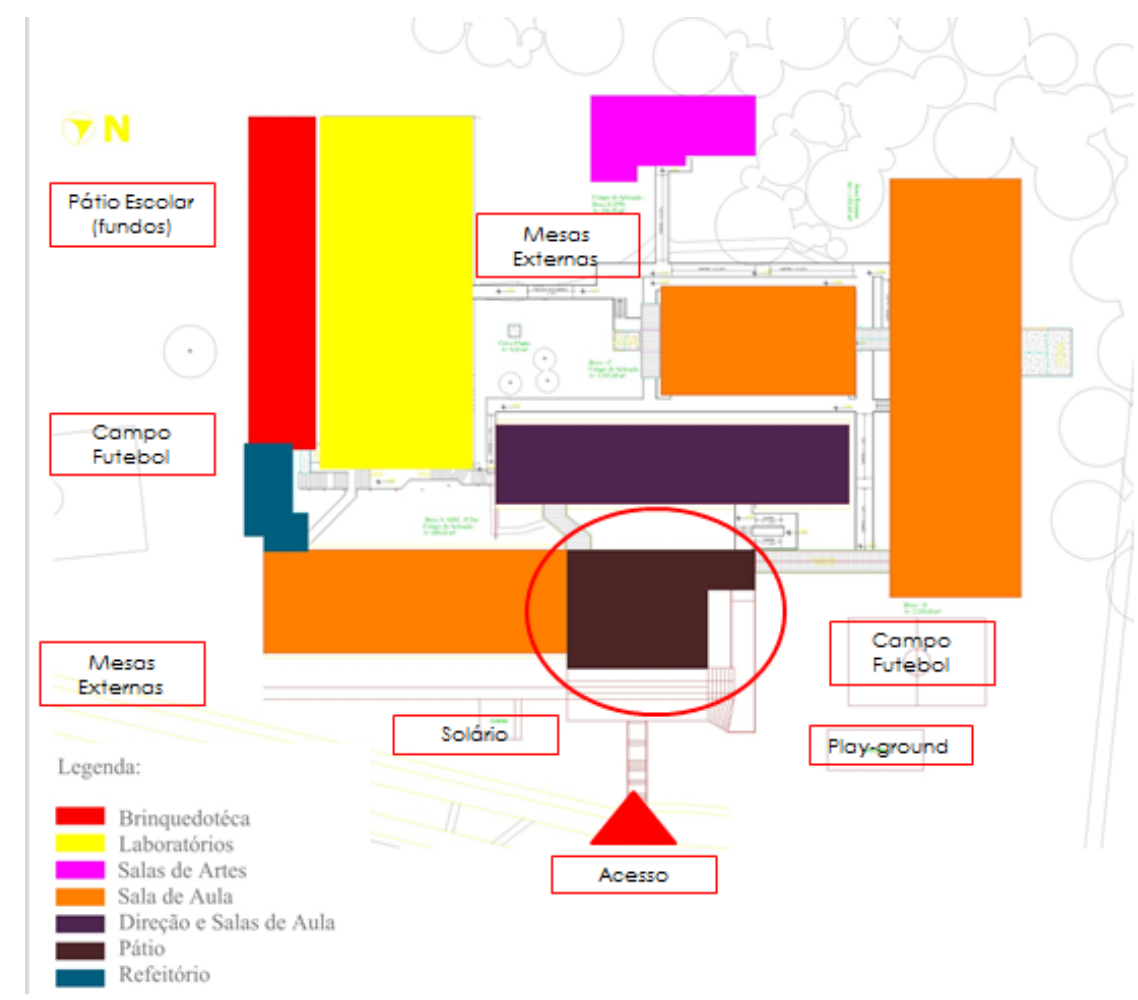

Figura 01 - Implantação Colégio Aplicação com destaque para o pátio do coberto, UFSC. Fonte: Escritório Técnico Administrativo (ETUSC) - UFSC, 2014.

O terreno amplo e com topografia acidentada permite que o Colégio possua implantação em platôs, com pátio externo dividido por atividades. A parte da frente possui parque infantil para crianças do ensino fundamental e um campo de futebol (figuras 02 e 03). Há também solário e mesas externas próximas ao refeitório (figura 04). Nos fundos do Colégio, há vegetação mais densa e ali não há delimitação de atividades (figura 05). 


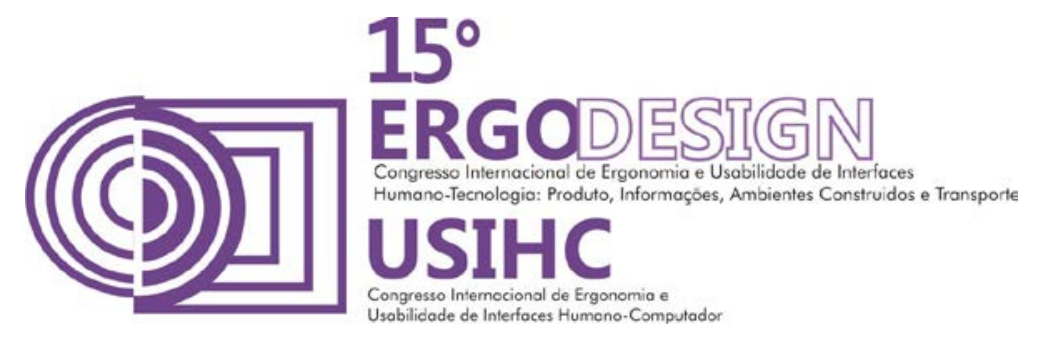

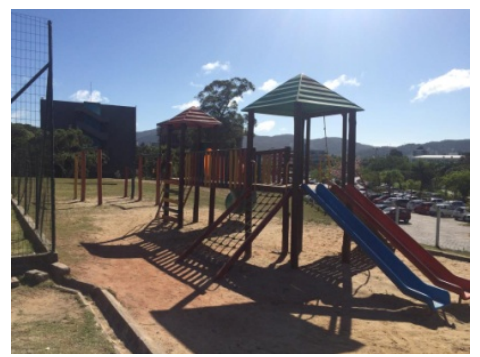

Figura 02 - Parque infantil. Fonte: RECH, 2014.

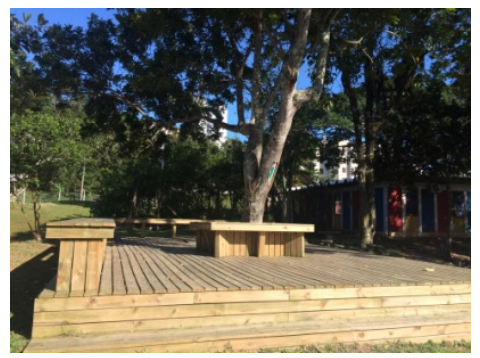

Figura 04 - Mesas externas. Fonte: RECH, 2014.

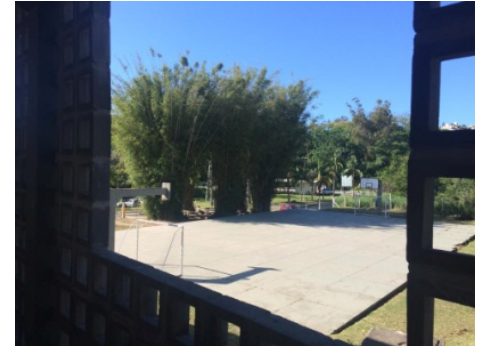

Figura 03 - Quadra de futebol. Fonte: RECH, 2014.

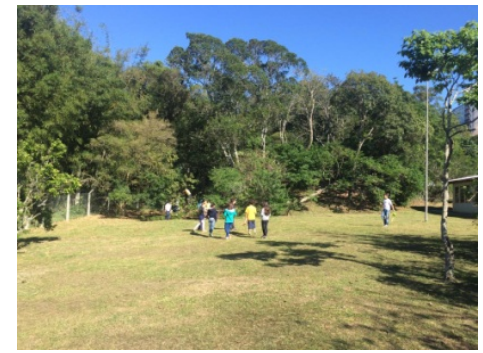

Figura 05 - Fundos do Colégio. Fonte: RECH, 2014.

Após o uso dos instrumentos metodológicos foi possível constatar o território do pátio escolar em cinco diferentes escalas espaciais: (1) do campus universitário e do Colégio de Aplicação público e privado; (2) o pátio externo na frente e nos fundos como sagrado e profano; (3) do pátio externo e do pátio coberto; (4) do pátio coberto e dos blocos; (5) dos usos atribuídos ao pátio coberto. Cada um deles será apresentado a seguir.

A relação estabelecida entre o Colégio e o campus universitário possui diferentes públicos. Por isso, e pela própria implantação numa cota topográfica mais alta e com uma rua tangenciando seu acesso principal, é possível identificar um primeiro território demarcado fisicamente pela via pública, os acessos de pedestre e de veículos (figuras 06 e 07), a guarita e a cerca.

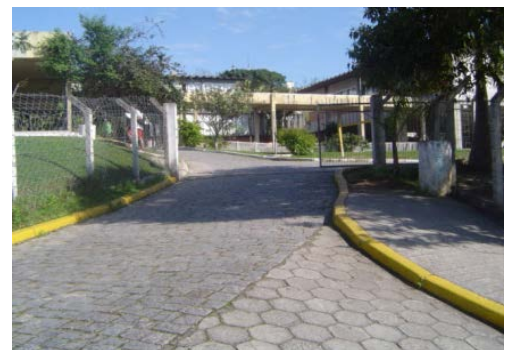

Figura 06 - Acesso ao estacionamento. Fonte: RECH, 2014.

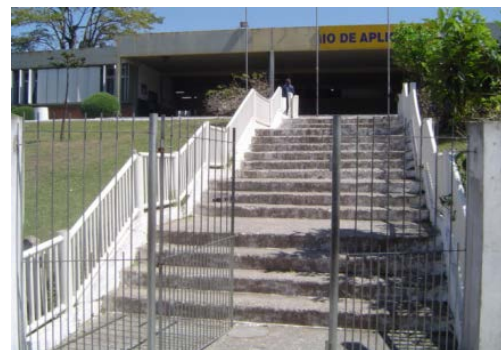

Figura 07 - Acesso principal. Fonte: RECH, 2014. 


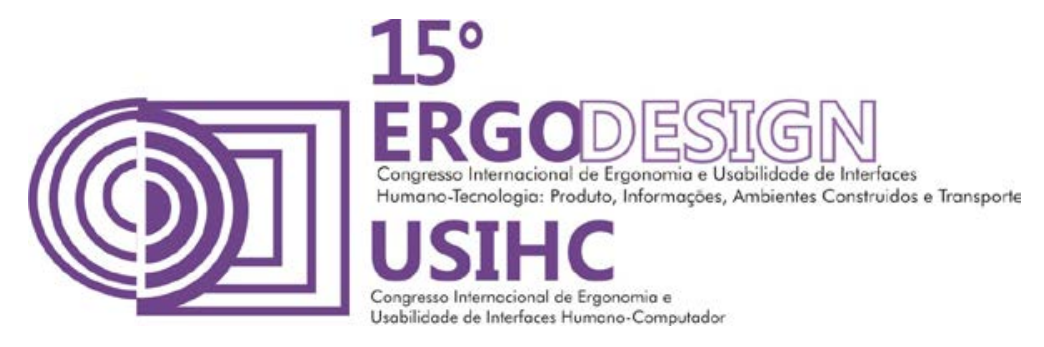

Dessa maneira é possível identificar graus de acesso, adotados por questões de segurança e controle. "No mundo inteiro encontramos gradações de demarcações territoriais, acompanhadas pela sensação de acesso" (HERTZBERGER, 1999, p.15). Mesmo o Colégio sendo um edifício público, é possível identificar o Campus como território público e a escola como privado.

O território estabelecido no pátio externo pode ser entendido como uma transição: sagrado e profano. As atividades desenvolvidas pelo Colégio nos fundos do pátio externo são com vigilância velada, dando às crianças a impressão de liberdade e de maior divertimento. Enquanto, as atividades que acontecem na quadra de esportes e no parque infantil na frente do Colégio são geralmente, monitoradas, entendidas como parte do aprendizado.

O terceiro território é compreendido pela sensação de dentro-fora (figura 08), dada pela cobertura do pátio do estudo. O plano base é elevado e a cobertura marca o vazio. É possível identificar a territorialidade também entre o pátio coberto - espaço de características semifixas - e os blocos - espaço de características fixas. Cada um dos blocos é entendido pelos usuários com uma função determinada e com ela uma organização espacial é pré-estabelecida.

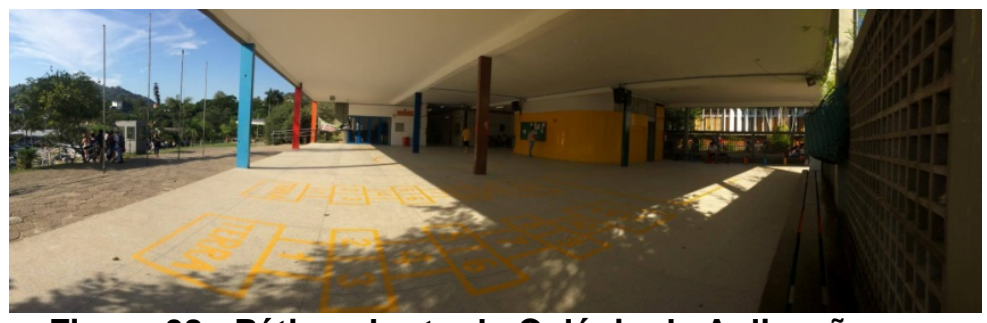

Figura 08 - Pátio coberto do Colégio de Aplicação.

Fonte: RECH, 2014.

O acesso principal do Colégio é também o único pátio coberto (figuras 09 e 10). O espaço é amplo, com laje plana e pilares de apoio. Há mobiliário nas bordas (bancos, lixeiras e murais) e possui piso pintado com grafismos geométricos. Além do uso de acesso e distribuição para os demais blocos da Escola, o pátio é apoio para atividades lúdicas nos dias de sol intenso ou chuva. Foi possível dividi-lo em três postos de atividades: (01) espaço livre de brincar, delimitado pelo desenho no piso (figura 11); (2) espaço de estar, com bancos lineares (figura 12); (3) acesso restrito, que se configura como depósito (figura 13).

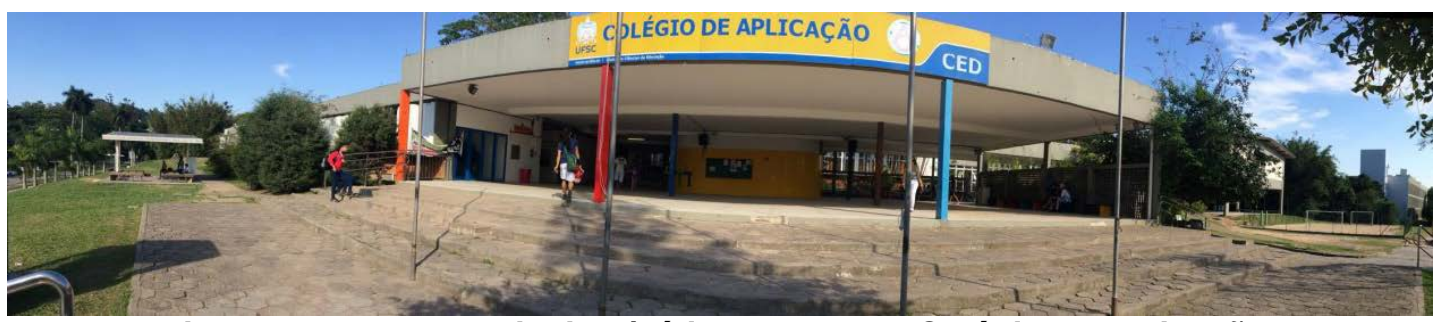

Figura 09 - Acesso principal/pátio coberto do Colégio de Aplicação.

Fonte: RECH, 2014. 

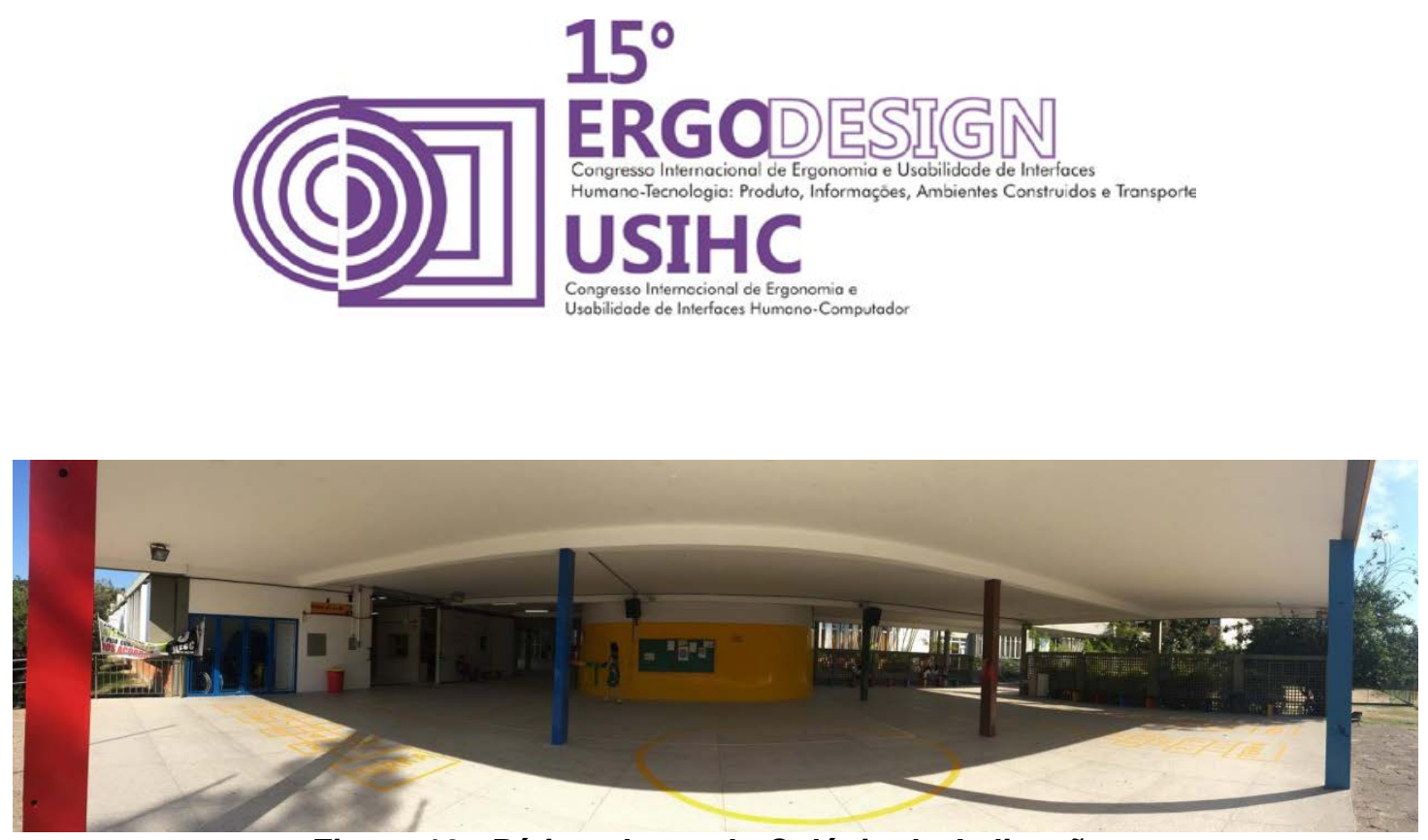

Figura 10 - Pátio coberto do Colégio de Aplicação.

Fonte: RECH, 2014.

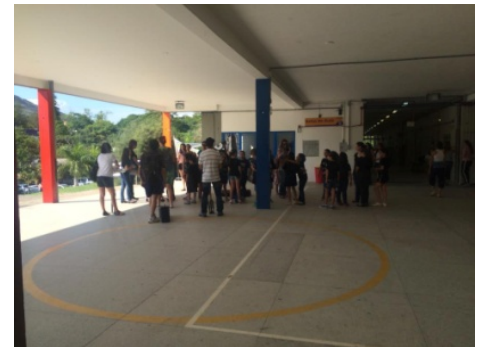

Figura 11: Posto 01. Fonte: RECH, 2014.

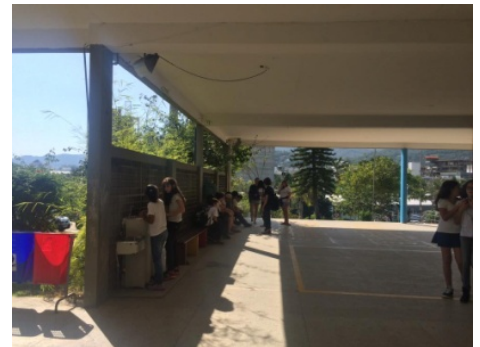

Figura 12: Posto 02.

Fonte: RECH, 2014.

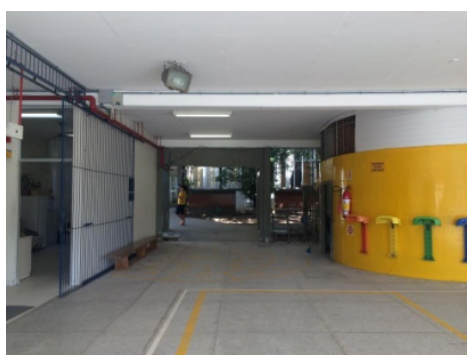

Figura 13 - Posto 03.

Fonte: RECH, 2014.

No pátio coberto, foi possível compreender que o Colégio (talvez por razões pedagógicas) buscou demarcar territórios a partir de usos. Há bancos nas bordas, murais com informações e desenhos geométricos pintados no piso (figura 14). Quando perguntadas o que representavam os símbolos, as crianças não souberam responder. O uso talvez seja mais eficaz quando as atividades são monitoradas pelos professores. É importante destacar que por razões pedagógicas e criativas, seja interessante que esses símbolos permitam livres associações e compreensões.

Foi possível analisar nos resultados que os territórios estabelecidos entre o Colégio e a cidade (representada pelo Campus); e os pátios externos e coberto são identificados. Neles, a arquitetura diferencia os espaços, atribuindo-Ihes significados. 


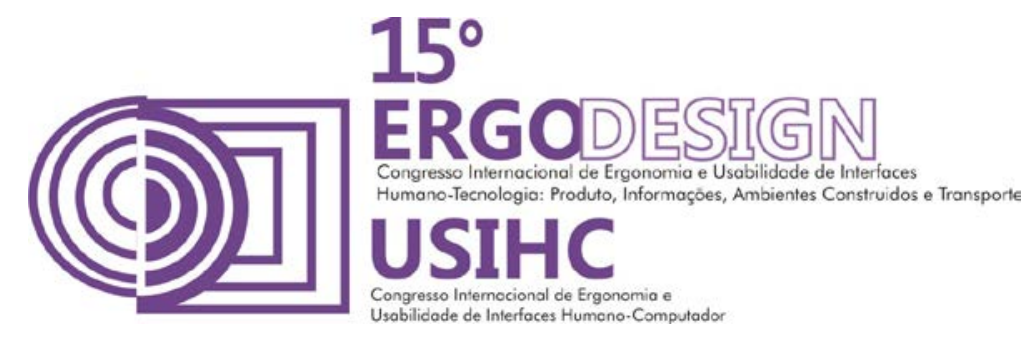

No entanto, a demarcação do território no pátio coberto não é compreendida da maneira que o Colégio propôs: definindo usos e limites. Segundo Hall (2005), as pessoas levam consigo esquemas de território interiorizados, aprendidos bem no início da vida. Dessa maneira é importante, que os postos de atividades tenham infraestrutura arquitetônica coerente com os múltiplos usos atribuídos, especialmente nos postos 01 e 02 em que as crianças são os principais usuários.

Por isso no posto 01, a paginação do piso é ineficaz às brincadeiras das crianças. Caso seja de interesse pedagógico, sugere-se que seja utilizado material de pintura mais duradouro e com maior contraste com o piso e com as condições de reflexão lumínica que o pátio apresenta.

O posto 02 configura-se como um espaço de passagem ou de permanência rápida, porque o mobiliário linear inibe a conversa em grupos maiores. Muitas vezes pode-se observar crianças sentadas no chão para formar rodas de conversa. Dessa maneira, sugere-se a disposição dos bancos permitindo conversas lado a lado e em grupos. Esses poderiam ter diferentes alturas, respeitando a ergonomia infantil. Lixeiras e bebedouros também, deveriam estar sinalizados.

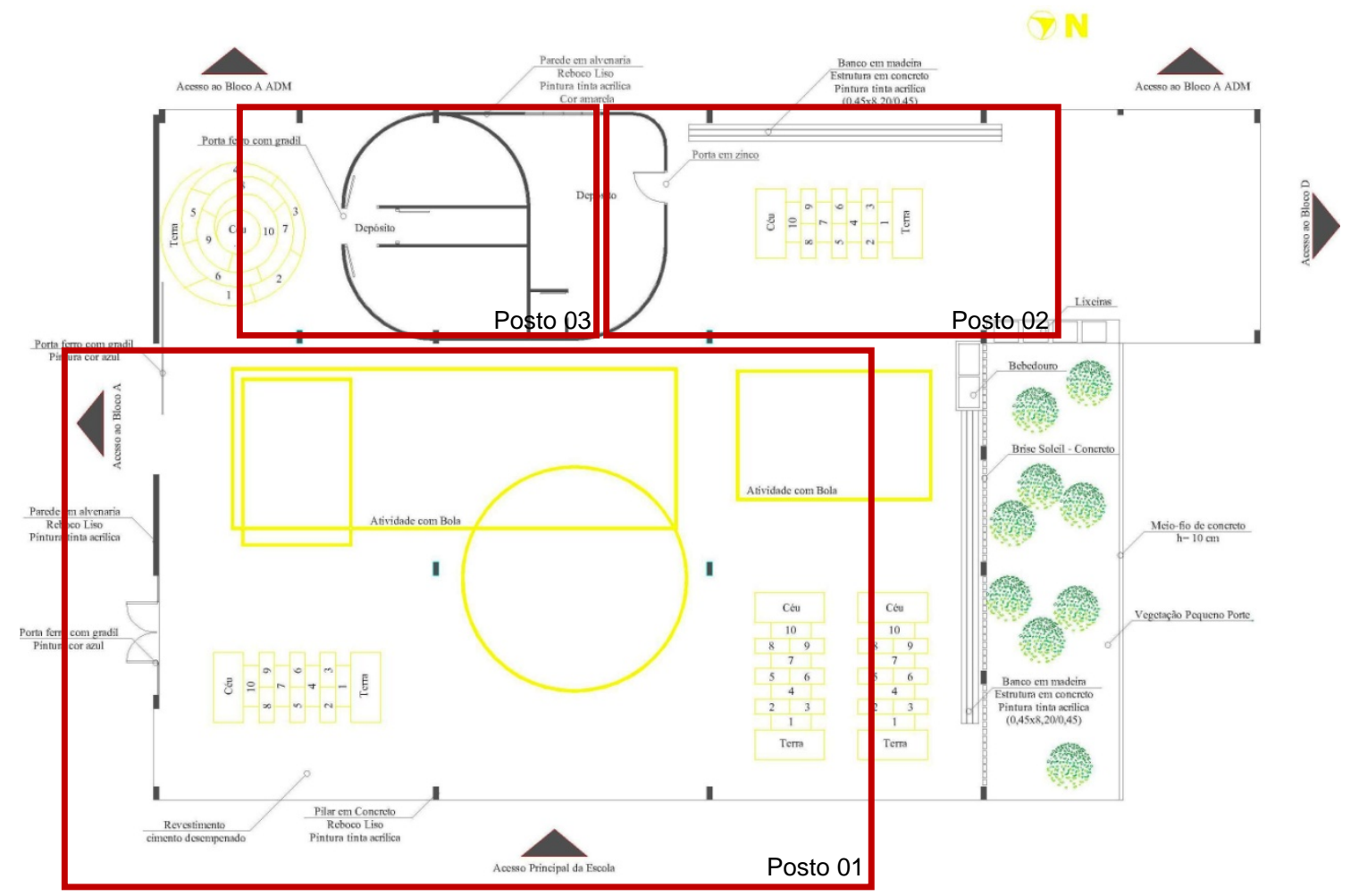

Figura 11 - Planta-baixa do Pátio coberto do Colégio Aplicação.

Fonte: Escritório Técnico Administrativo (ETUSC) - UFSC, adaptado pelas Autoras, 2014.

\section{CONSIDERAÇÕES FINAIS}

A preocupação com o espaço/ambiente destinado à educação está presente em diversas 


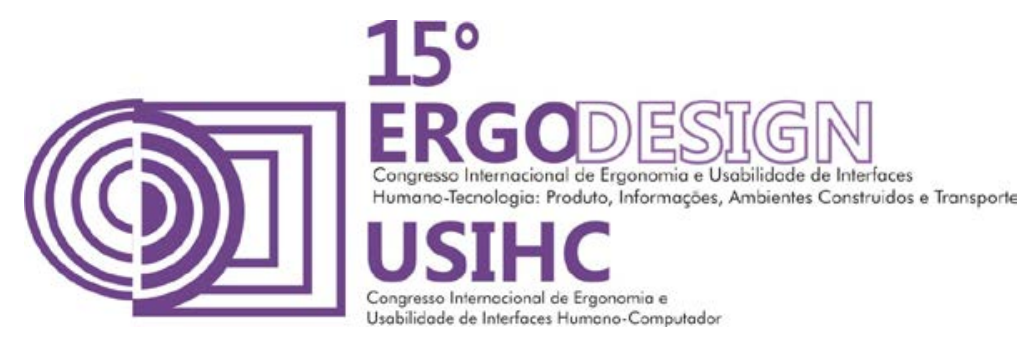

propostas pedagógicas, como Freinet e Montessori, cada um de acordo com seus pensamentos. Para a infância, as dimensões do espaço e do tempo ao se agregarem com o grupo social produzem arranjos culturais carregados por toda a vida.

Frente essas condições, reforça-se a necessidade de rever conceitos arquitetônicos no sentido de garantir que os ambientes externos também sejam planejados para oferecer segurança, desafios e aguçar a curiosidade infantil.

"Fortalecendo a finalidade social dos pátios e os demais espaços livres como lugares simbólicos da educação e da vida coletiva e criando trilhas urbanas de maneira que estruturem novos arranjos educativos [...]" (FARIA, 2011, p.43).

Os territórios na escola são fundamentais para formação da identidade da criança. Nos pátios, podem permitir a experiência com o lugar e ensinar sentimentos de afeição ou desprezo consciente ou inconsciente, que poderão ser levados para toda a vida.

\section{REFERÊNCIAS BIBLIOGRÁFICAS}

ALMEIDA, Maristela Moraes. Análise das interações entre o homem e o ambiente. Dissertação de Mestrado em Engenharia. Florianópolis: UFSC, 1995. Disponível em: <http://www.eps.ufsc.br/disserta/maristela>. Acesso em 16 de nov. de 2014.

AZEVEDO, Giselle Arteiro Nielsen; RHEINGANTZ, Paulo Afonso. TÂNGARI, Vera Regina (organizadores). O lugar do pátio escolar no sistema de espaços livres: uso, forma e apropriação. Rio de Janeiro, UFRJ/FAU/PROARQ, 2011. 203 p. (Coleção PROARQ)

BINS ELY, Vera Helena Moro. Acessibilidade Espacial - Condição Necessária para o Projeto de Ambientes Inclusivos. In: MORAES, Anamaria (org.). Ergodesign do Ambiente Construído e Habitado: Ambiente Urbano, Ambiente Público, Ambiente Laboral. Rio de Janeiro: IUsEr, 2004. 146pg.

Vera Helena Moro. Ergonomia + Arquitetura: buscando um melhor desempenho do ambiente físico. In: Anais do $3^{\circ}$ Ergodesign - $3^{\circ}$ Congresso Internacional de Ergonomia e Usabilidade de Interfaces Humano-Tecnologia: Produtos, Programas, Informação, Ambiente Construído. Rio de Janeiro, RJ: LEUI/PUC-Rio, 2003.

FARIA, Ana Beatriz Goulart de. O pátio escolar como ter[ritó]rio [de paisagem] entre a escola e a cidade. In: AZEVEDO, Giselle Arteiro Nielsen; RHEINGANTZ, Paulo Afonso. TÂNGARI, Vera Regina (organizadores). O lugar do pátio escolar no sistema de espaços livres: uso, forma e apropriação. Rio de Janeiro, UFRJ/FAU/PROARQ, 2011. 203 p. (Coleção PROARQ)

GONÇALVEZ, Fábio Mariz; FLORES, Laís Regina. Espaços livres em escolar - Questões para debate. In: AZEVEDO, Giselle Arteiro Nielsen; RHEINGANTZ, Paulo Afonso. TÂNGARI, Vera Regina (organizadores). O lugar do pátio escolar no sistema de espaços livres: uso, forma e apropriação. Rio de Janeiro, UFRJ/FAU/PROARQ, 2011. 203 p. (Coleção PROARQ)

HALL, Edward Twitchell. A dimensão oculta. São Paulo: Ed. Martins Fontes, 2005. 258 p.

HEIDEGGER, Martin. Ser e tempo. 12.ed. Petrópoles, RJ: Vozes; Bragança Paulista, SP: Universidade São Francisco, 2002 - 2004. 2 v. (Pensamento humano). 


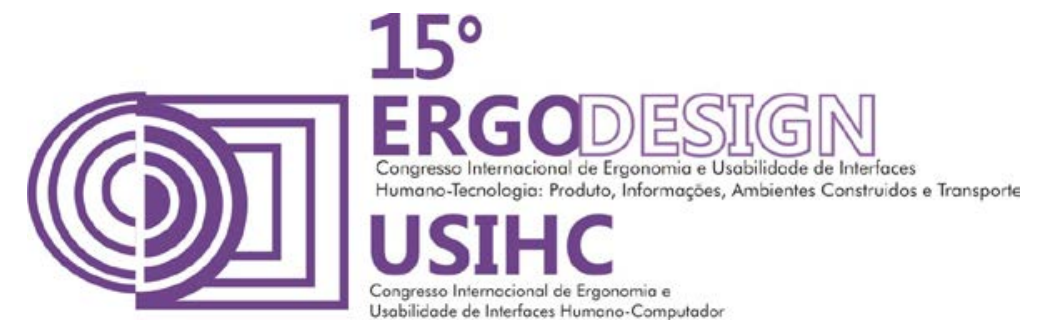

HERTZBERGER, Herman. Lições de arquitetura. 2.ed. São Paulo: M. Fontes, 1999. 272 p.

KOWALTOWSKI, Doris C.C.K. Arquitetura escolar: o projeto do ambiente de ensino. São Paulo: Oficina de Textos, 2011. $270 \mathrm{p}$.

MARCONI, Marina de Andrade; LAKATOS, Eva Maria. Técnicas de Pesquisa: planejamento e execução de pesquisas, amostragens e técnicas de pesquisa, elaboração, análise e interpretação de dados. 3. ed.rev. e ampl. São Paulo: Ed. Atlas, 1996. 231 p.

OKAMOTO, Jun. Percepção Ambiental e comportamento: visão holística da percepção ambiental na arquitetura e na comunicação. São Paulo: Ed. Mackenzie, 2002. 261 p.

RIBEIRO, Lúcia Gomes; MONT'ALVÃO, Claúdia. Ergonomia no Ambiente Construído. In: MORAES, Anamaria (org.). Ergodesign do Ambiente Construído e Habitado: Ambiente Urbano, Ambiente Público, Ambiente Laboral. Rio de Janeiro: IUsEr, 2004. 146 p.

SARMENTO, Manuel J.; PINTO, Manuel (1997). As crianças e a infância: definindo conceitos, delimitando o campo. In: SARMENTO, Manuel J.; PINTO, Manuel (organizadores). As crianças contextos e identidades. Centro de Estudos da Criança. Universidade do Minho. Portugal.

TRANCIK, Anika M.; EVANS, Gary W. Spaces Fit for Children: Competency in the Design of Daycare Center Environments. In: Children's Environments. Colorado, v. 12, n. 03, 1995. p. 43-58. Disponível em: $<$ http://www.colorado.edu/journals/cye $>$. Acesso em 23 set. 2006. 